\title{
Technology as Thirdspace: Teachers in Scottish Schools Engaging with and Being Challenged by Digital Technology in First COVID-19 Lockdown
}

\author{
Jonathan Brown, Carrie McLennan, Daniela Mercieca, Duncan P. Mercieca *, Derek P. Robertson (D) \\ and Eddie Valentine
}

check for updates

Citation: Brown, J.; McLennan, C.; Mercieca, D.; Mercieca, D.P.;

Robertson, D.P.; Valentine, E. Technology as Thirdspace: Teachers in Scottish Schools Engaging with and Being Challenged by Digital Technology in First COVID-19 Lockdown. Educ. Sci. 2021, 11, 136. https://doi.org/10.3390/

educsci11030136

Academic Editor: Palitha Edirisingha

Received: 26 February 2021

Accepted: 16 March 2021

Published: 21 March 2021

Publisher's Note: MDPI stays neutral with regard to jurisdictional claims in published maps and institutional affiliations.

Copyright: (c) 2021 by the authors. Licensee MDPI, Basel, Switzerland. This article is an open access article distributed under the terms and conditions of the Creative Commons Attribution (CC BY) license (https:/ / creativecommons.org/licenses/by/ $4.0 /)$.
School of Education and Social Work, University of Dundee, Nethergate, Dundee DD1 4HN, Scotland, UK; j.v.brown@dundee.ac.uk (J.B.); C.McLennan@dundee.ac.uk (C.M.); dmercieca001@dundee.ac.uk (D.M.); d.p.robertson@dundee.ac.uk (D.P.R.); e.valentine@dundee.ac.uk (E.V.)

* Correspondence: dmercieca002@dundee.ac.uk

\begin{abstract}
This paper looks at the impact of digital technology on teaching and learning in primary schools in Scotland during the first COVID-19 lockdown from March to June 2020. The pandemic has challenged our understanding of schooling as, for the first time in many years, schools as we know them were shut and the school building was removed as the site of teaching and learning. This paper uses the concept of Thirdspace as developed by Edward Soja (1996), where Thirdspace is understood as an in-between space between binaries that enables the possibility to think and act otherwise. Drawing from qualitative data from interviews with primary school teachers, this paper explores how the lockdown in general, and digital technology in particular, facilitated a Thirdspace in the first COVID-19 lockdown. Findings from the study indicate that engaging with digital technology offers the teacher more possibilities than they have come to expect in the physical space of traditional schooling.
\end{abstract}

Keywords: digital technology; home-learning; Thirdspace; primary teachers; Scotland; COVID19 lockdown

\section{Introduction}

Schooling is a fundamental part of society's fabric. The interruption to established forms of learning in schools presented challenges to education systems across the globe. These challenges highlighted levels of unpreparedness of teachers in terms of their digital technical competence and digital pedagogy. The previous experience of viral epidemics, as experienced in countries such as Hong Kong, led to the systematic training of teachers in the use of digital technologies [1]. However, while the real experience of such an event caused this pre-emptive approach to be taken, in other countries such as Germany, France and Italy [2], there has been what may be described as a lag in the expected impact of their investment in the digital on the transformation process of their education systems. In Australia [3], it was reported that students, parents and teachers found that communication in lockdown to be a real challenge with the effective strategies for the use of digital technologies in lockdown remaining unclear. It is interesting to note that, in Darling-Hammond et al.'s [4] examination of teaching systems around the world, no mention is made of improving digital connectivity or of digital tools for learning. Indeed, when discussing how to prepare learners for the 21st century (pre-COVID-19) world, what are flagged as important are factors such as teacher professionalism, dynamic curricula, critical thinking skills and student-centred pedagogies. It is as if there is an assumption that the physical school space is the locus of learning in perpetuity. There does not seem to be any mention of digital skills as having value.

It is against this wider backdrop of disruption, challenge and uncertainty that we turn our eyes to the Scottish context for the purposes of our study. In Scotland, education 
has long been perceived and valued as key to social mobility and a means of promoting democracy [5]. This key role of schooling has been challenged by the COVID-19 pandemic as schools as we know them were closed in many countries. According to the United Nations Policy Brief [6] in April 2020, 188 countries imposed countrywide school closures, affecting more than 1.5 billion children and youth (p. 2). This unique phenomenon has, over the period of COVID-19 restrictions, led to a renewed acknowledgement and appreciation of the role of schools within society, and of those who work in schools. However, in the initial period of lockdown in March 2020, educators had to wrestle with how to teach adaptively to meet the needs of all learners, having been plunged into a completely novel situation. According to Darling-Hammond [7], adaptive teaching requires, "deep and sophisticated knowledge about learning, learners, and content" (p. 77); lockdown meant that an additional factor came into stark relief which was namely how to reach and interact with the learners when the physical school space was no longer available in the traditional way. Therefore, lockdown meant that the spotlight was focussed on the purpose of digital tools and spaces for teaching and learning. This lockdown-induced interruption to schoolbased learning in familiar physical spaces required, and expected, Scottish teachers to begin to use a range of digital communication and presentation tools so that teaching could be transferred online. For some teachers this was their first time engaging with digital technology for more than basic needs. The requirement to transfer teaching to this media was such that not only did Scottish teachers have to familiarise themselves with the technical functionality of tools such as Microsoft Teams or Google Classroom, but they also had to rise to the challenge of thinking about effective learning design and pedagogy in the digital space.

This paper focuses on the role that technology played during this time, but this needs to be seen within a discourse of teacher identity working in a context outside of a school building. We refer to the concept of Thirdspace as argued by Edward Soja [8] to help us think about in-between spaces in binaries. The guiding question of this paper is: how did digital technology manifest as a facilitator of Thirdspace in COVID-19 lockdown?

\section{Methodology}

\subsection{Aims and Subject of the Research}

This paper draws from a qualitative study that was conducted during the first COVID19 lockdown in Scotland. We authors are part of a larger group of researchers from the School of Education and Social Work at the University of Dundee, all of whom were keen to capture the impact of this unprecedented event on the lives of children, their families and educators. We were 'curious' about what they made of their current experiences of work and the contribution of this to their thinking about what is valued in their work as a teacher or Head Teacher as they supported children's and families' learning during the lockdown. The wider project was led by the following research question: What are primary school educators' experiences of teaching from home/in hub during the COVID-19 lockdown in Scotland?

\subsection{Research Procedure}

A decision was taken to carry out qualitative research with teachers and Head Teachers working in Scottish primary schools. Such a choice was based on the knowledge of the kind of data that we wanted to gather, which gave detailed insights into the lived experiences of those agreeing to be interviewed. Starting from the second week of lockdown in March until June 2020, teachers and Head Teachers in primary schools in Scotland were invited through different social media platforms to participate in an in-depth interview to capture their lived experiences in real time. These online interviews were carried out through MS Teams.

The process of analysis of the interviews for the purpose of this paper can be visualised in the form of two spirals which seem to weave closer and closer together as they progress. These are constituted by our reading of Edward Soja [8] and our growing awareness of 
the prominence of the theme of digital technology in the interviews we were listening to and transcribing. The authors of this paper embarked on reading about Thirdspace, while at the same time becoming more and more immersed in the data. As Hollway and Jefferson [9] stress, "after a whole day working on the transcripts ... (a process we often referred to as 'immersion') we would be inhabited by that person in the sense that our imagination was full of him or her" (p. 69). The authors met online several times to discuss their thoughts about the literature read and the interviews, and started to explore themes that emerged, following Hollway's idea that the significance of the interviews is not only "a property of the extract, but of the work it is put to do" [10] (p. 36). This was thus a theory-led thematic analysis [11] based on the works of Soja [8], where both theory and interviews were 'speaking' to each other while at the same time challenging each other.

\subsection{Building a Research Tool}

The nature of the research question did not lend itself to an organised survey leading to statistical analysis. Since we sought the perceptions and meanings created of the events that were unfolding and their impact on participants, an in-depth interview was the preferred method of collecting this information. Following discussions with the wider research team, ten questions were chosen to guide the interviews, and all interviewers worked with the understanding that this was to be a conversation. Indeed, interviewers reported that most participants needed little prompting as they were very articulate and fluent. Some participants reported that they welcomed such conversations and thought that it gave them space to pause and reflect on what they were engaging with in unique times, a chance to take stock on all that they had accomplished in a short span of time and under intense pressure.

\subsection{Characteristics of the Research Group}

More than sixty primary school teachers and Head Teachers volunteered to participate in the project and were interviewed. The respondents volunteered themselves as participants and all those who did, and who fit the parameters of working in primary schools in Scotland, were accepted. The research group did not seek a representative sample of educators which was distributed according to certain criteria. This was because, although cognizant of the large variety of contexts in which Scottish schools in different geographical and socio-economic areas function, we were not seeking a sociological understanding of their experiences, as much as we sought the educators' personal thoughts about these experiences. We do not claim to be able to generalise our findings to represent the experience of all primary school educators. As Wendy Hollway [10] suggests, "generalizability... [in this kind of research] ... has to be established according to theoretical rather than statistical principles" (p. 16). In the Rogerian sense of what is most personal is most general [12], we believe that the issues emerging from our process of analysis are generalisable conceptually and theoretically. We have had several reports in our online seminars about this project that viewers have resonated with the participants' expressed thoughts and feelings.

We feel the need to clarify that the interviews were reflecting the experiences of participants who were willing to share their story. It should be noted that there are others whose stories may not tally. Yet, there have been many who have 'recognised' our interpretations and analyses, "that is, the sense that we made out of them can be shared through the subjectivity of others" [9] (p. 80) "Our work, as well as being theoretically led, is solidly empirical in the sense that supporting and challenging evidence is available" [9] (p. 80).

\subsection{Research Ethics}

Ethical clearance was sought and given by the School of Education and Social Work at the University of Dundee. High in our consideration was the awareness that this was rather a stressful time and that our research should not in any way add to pressures on interviewees. Voluntary participation was key, and when educators expressed interest in 
participating, the interviewers took pains to ensure that the time of the interview suited the many claims on the participants. The interview questions were also placed on an online survey tool for those who were keen to participate but felt that they could not find an hour to be interviewed. A few educators opted for this online survey. Besides this, confidentiality and anonymity were naturally very important, as we made sure not only that identifying information was not divulged, but also disguised information of third party persons, places or events which were mentioned.

\subsection{Limitations of the Study}

The urgency of starting the research project as soon as the lockdown in Scotland commenced meant that the teachers were invited to participate through social media. We are aware of the possibility of these respondents presenting as models of hard work and enthusiastic professionalism. We have mentioned elsewhere that these need to be seen as experiences of people willing to share their story and that there are others whose stories may not tally. The voices of these teachers are not captured in our research. A longitudinal study on the impact of the pandemic restrictions on teachers and teaching may capture the narratives of those whose life journeys have been affected significantly.

\subsection{Theoretical Framework}

The data was analysed through a theory-led thematic analysis [11]. This paper understands teachers' identities as multi-layered, complex and continually becoming(s). Yet, in this unprecedented event, which happened with very little warning, teachers were forced to make numerous changes over a short time. Elsewhere, we outline the toll such changes had on teachers and others $[13,14]$. In this paper, we focus on "the change process [itself], and in particular when a person is in between two identity constructions: when they are neither one thing nor the other" [15] (p. 286). This 'change process' often is uncertain and dilemmatic in nature. Change processes allow for "in between spaces" [15] (p. 2) to reside in the "overlap and displacement of domains of difference" (p. 2). Difference is often produced through thinking that occurs in binary opposites, with our teachers trying to come to terms with the change from teaching pre-COVID-19 and teaching during COVID-19.

Thinking in binaries does not allow "both/and also", what Soja [8] (p. 5) refers to as Thirdspace. He seeks to acknowledge Thirdspace and invites us to follow suit, as Thirdspace allows for creative combinations and restructuring of ideas that can provide new alternatives to binary thinking [2] which is often oppositional. In particular, when structure and agency are seen as 'both/and also', this allows "our understanding of selfidentity/social-identity mutual construction" [16] (p. 286) to be viewed in a new light. The acknowledgement allows possibilities of thought which are otherwise stunted-thus the act of acknowledgement is powerful and can even be liberating. It disturbs the established to and fro of the binary. Soja draws upon Foucault's term 'heterotopia' [8] (p. 145) to describe the Thirdspace as 'other', as a space that is disturbing, intense, incompatible, contradictory or transforming. Heterotopia is a "thirding-as-Other" [8] (p. 5), 'a more space', 'an added space' 'a different space' than what we 'normally' understand and live by. Soja's words capture this: "set aside the demands to make an either/or choice and contemplate instead the possibility of both/and logic" [8] (p. 5). We can think of Thirdspace as a space that allows us to "draw selectively and strategically from the two opposing categories to open new alternatives" [8] (p. 5). The application of Thirdspace theory to the digital realm was proposed by Potter and McDougall [17], who posited that websites and online spaces could act as "a negotiated and contested area in which meanings are made and shared, some of which may relate to encountering new knowledge, learning or developing new skills and dispositions," (p. 7). This study is situated within this definition, where contradictory and opposing categories (First and Second space) can work together to generate new knowledges [18] (p. 42) and extend beyond these spaces. 
The school lockdown brought to the forefront several binaries which have structured teachers' lives, for example personal and professional, school-time and home-time, teaching and learning. We argue that the lockdown allowed for a third space to emerge, a space where 'everything comes together' [8] (p. 56). Technology has been hailed as a saviour in this scenario, as enabling processes which would otherwise have abruptly stopped. This paper problematises this view of technology within a number of binaries. Through the concept of Thirdspace we think about the possibility of re-imagining (and inhabiting) an alternative space for primary teachers working with technology during COVID-19 school lockdown.

\subsection{Context}

Digital technologies in education have long since played a part in the discourse surrounding the transformation of Scotland's education system. Scotland was one of the first countries to develop a national intranet (Glow) for all teachers and learners. This national intranet, started in 2006, has long since been at the vanguard of digital technology's efforts to become embedded in the "habits of the mind, habits of the heart, and habits of the hand" of Scottish teachers [19] (p. 59). Even though this initiative has cost upwards of $£ 69$ million [20] and was also the recipient of the internationally coveted George Lucas Award in 2008 [21,22], it is a platform that has, until very recently, struggled to play its hoped-for part in the digital transformation of teaching and learning in Scotland. Recent years have seen the range of services offered to teachers and learners by Glow improve. Yet, questions remain about how their effective use have become central to the practice of teaching and learning in our schools. Indeed, the recent Enhancing Learning and Teaching through the use of Digital Technology Strategy noted that "despite the pervasive nature of digital technology, its benefits are not always fully felt within our education establishments" [20] (p. 3).

It is interesting to note that although it has been four years since this strategy paper, these concerns are still being raised. In the recent report by the Scottish Government's International Council of Education Advisers, it was stated that it was felt that there were still "students and teachers with insufficiently developed digital skills" [23] (p. 8). The report acknowledged that there had been recent national developments to begin to positively address this ongoing issue and stated that, "there is now a need to exploit the potential contribution of interactive digital pedagogies for the various purposes of the curriculum" [23] (p. 10).

On 20 March 2020, schools in Scotland were closed to students unless they were classed as vulnerable or children of key workers, in which case they would be allowed into "hubs" to be supervised, although their class-based learning would be carried out at home. The Education Minister announced on 19 March that children's education would continue via distance and online learning with as much continuity as possible [23]. It was another month before Scottish Government gave further information [24] in relation to the school term from April to June. This statement indicated that there would be ongoing guidance in relation to working digitally, support for teachers, and equity of support for home learning and children with Additional Support Needs. It was clarified that parents would not be expected to engage with their children's learning formally nor to act as teachers. The nature of the educational infrastructure in Scotland meant that this could be interpreted and enacted differently at local authority and school level.

\section{Results}

Three themes are developed in this section.

\subsection{Theme One: Knowing-Not Knowing; Valuable-Not of Value}

As mentioned earlier, the use of technology has been growing steadily in education. The data points to a pre-COVID-19 state where groups of teachers had various attitudes towards the inclusion of technology in their teaching. Respondents referred to these 
attitudes in themselves and their colleagues in terms which were rather polarised. Their responses also indicated a linear progression within their own thinking about technology, referring to tensions about not knowing and not valuing technology enough.

One teacher, a technology champion in her school, had, prior to lockdown, been offering weekly support to her colleagues with their technology issues. She reported that over three years she had only had a handful of people going to her for support. She felt that her colleagues did not value technology and did not put in enough effort to know more:

This is my third year in this current school, and I spent those three years up until the last week before school closure having those colleagues tell me that they are not interested in digital literacy, they hate it. I provided a drop-in session every week and in three years, I had three people come, so every Wednesday after school I spent time in ICT suite offering to help them train them because they all said that they were being deskilled. I was demotivated by that whole kind of scene in my in my setting. So that's completely changed with the schools' closure. And, uh, my days I can hear my phone and my iPad, my school laptop, my own laptop, and it literally starts about 7:30 in the morning. Ding Ding, Ding, Ding and I can be sorting out problems until 11:00 o'clock at night, and I mean my steps have gone from thousands to less than 1000 ... I've been so busy in this lockdown.

During lockdown, technology use increased dramatically. It became the sole medium through which teaching took place. The interviews show that many teachers were experiencing a rather steep learning curve with this medium and that many were struggling. It became a new source of stress that technology became the new interface through which teachers were deemed as 'good' or otherwise. The interviews reflected how teachers were constructing themselves and their colleagues in a discourse of competence.

Several teachers felt under pressure because their work now was directly accessible to the parents, where previously this used to be mediated through students. Now that everything was online, and young children needed parental support to access work, teachers felt their work was 'scrutinized' by parents:

you just do so much of teaching just off the cuff and, you know, my activities and learning experience are all planned but you don't plan everything you say until it comes out your mouth, whereas I'm very aware that parents are just seeing it online, like everything that I'm doing and putting out as being utterly scrutinized by some quite demanding parents. So, I am very aware of what I'm sending out, that it's got to be good.

This has influenced parental perceptions and constructions about teachers. Some Head Teacher respondents reported becoming aware that their teachers were now being gauged by parents differently:

What's been interesting to me as the headteacher and what I've learnt is the members of the staff team who are very good practitioners on the ground aren't necessarily coming across like that in the digital world. So I've had lots of wonderful messages from parents saying, 'Mr X is amazing, or Miss $\mathrm{X}$ is like this, she's brilliant', and I'm actually like, do you know what, in the classroom, their practise isn't matching the level of praise that they're receiving now publicly. Whereas I have some really good classroom practitioners who are very experienced, who know the curriculum inside out, and who will do their very, very best by their children, but in terms of their ability to be able to cope and operate with Teams and upload work, isn't matched, and so I have parents emailing in saying, 'I'm not getting this from that teacher, I'm not getting that'.

Such comparative thinking was also reflected in the teachers' interviews as they constantly compared face-to-face to online teaching, thus pointing out another binary. One teacher described that she no longer benefits from the instant reaction of her students and feels that she engages in more explanatory teaching because of this lack. We need to point 
out that, in the first lockdown, many schools in Scotland were following regulations which did not allow live online interaction to take place.

I think it made me realize how much I assume that the children know without it being explained, I think you get to know your class so well that they know what you mean in a way that parents don't. So, I think, OK, well, that explanation would have totally sufficed in the classroom, and it's not at all, you know, I've had to really think about how I explain things and how I word things. I realize how much I rely on instant feedback from the children. Because you get feedback, you know, a hundred times a minute in the classroom and by their faces and you don't have that at all when you're saying 'work this out on MS Teams' and then you're just left...

Several issues can be raised here, but certainly there is a need to question how technology was being used. Some teachers reported that after using technology for a while, it seemed to become

really stagnant, so I'm finding online teaching very repetitive, and that's not how I am day to day in a classroom. I'm usually always thinking of new things, new ideas, so I've sort of challenged myself ... Trying to do teaching videos as well. Nothing live".

There was also a reported difference between schools who had been engaging with technology prior to the lockdown and those who had not. Some teachers reported that their teaching had embedded technology across the whole school. Students were given tablets, and these were taken daily to schools and are used as part of their learning. The following quotation taken from an interview carried out only a few days into lockdown captures the almost natural flow to online teaching and learning: "I've already put my students into groups and I've assigned them books so that I can lead on my comprehension, I can set them task comprehension related to their books. Not all teachers are going to be doing that [in other schools], they don't know how to". The following quotation reports a very different perspective to the last:

I've heard a lot of people say that it is a waste of time teaching P1 [children aged 5 years] how to login and how to use a computer. I've had really good friends that have taught $\mathrm{P} 1$ and have removed all digital technologies from the classroom because that's not what P1s should be doing ...

\subsection{Theme Two: Teachers as Parents-Parents as Teachers}

Teachers and Head Teachers were asked about how they were experiencing the lockdown, and how they balanced working from home and caring for their families. The binary between the professional and personal/familial was challenged by restrictions imposed because of the COVID-19 pandemic and these boundaries were sometimes completely permeable. This was one of the factors which contributed to our growing appreciation of the impact of the school building on the running of the school, and the impact of the lack of it during lockdown. Teachers reported that not being in schools had an impact on them, even changing what had prior claims to their attention: 'when I am in a classroom, I do not answer a text message from my son, when I am in my kitchen, I do'. Geographical spaces imply distances and proximity, and this was a crucial factor in schools' closure. Students were not directly in front of teachers in classrooms but were at a distance (in their respective homes) online. Changing territorial lines produces new territory and what was once familiar is made strange. This second section concerns how teachers re-negotiated their lives and especially the demands made by technology on their time and/or attention [25].

It was evident that many teachers' personal lives and stories were being juxtaposed with their online presence. Many teachers reported that they felt very stressed:

It was, I have to say it was extremely stressful, the first Monday, Tuesday, Wednesday the adrenaline kicked in but, of course I have a daughter who's immunesuppressant so, you know, it's been a big worry about what my role has been to 
not take anything home to her. My husband and my son are, and my daughter, because they are in their 20s my children, they have all been furloughed. It's like they're coming to terms with being at home but I'm still working, you know. My son is a typical 21 year old and you know, wanting fed and attention and he gets bored so, you're trying to work down here and they are rambling about and interrupting, you're stressed enough with what's going on and the general situation and then they are interrupting every $5 \mathrm{~min}$ and you are trying to get, your head around how can I help vulnerable children ... it's, it's not great. It's not a great situation.

Many teachers spoke of moving their family lives and timetable to fit around their working hours; this was evident with teachers who were parents and carers of young children. "I keep my kids up later so that I can do work in the morning". Teachers recognise that they are getting to spend more time with their families and enjoying the moment:

in some ways it's lovely because I'm at home and I never get to be at home as well as teaching, I teach and I also tutor four different kids a week and I coached gymnastics two nights a week, so normally I'm really busy and I'm never in my house. I mostly I leave for school at 7:00 in the morning and because of either tutoring or gymnastics or children's activities. I'm generally not home for my tea till after 9, so it's actually been really nice to have more time in the house. Working-wise, it's challenging because it's a small house and my husband's also working from home and he's very noisy. Skype calls pretty much all the time and I've got two children who are also needing time and attention.

Some Head Teachers had to intervene and support teachers directly to help them reduce stress since they felt the need to be constantly online:

I had one member of staff say, she went online just to check one piece of work that she knew was coming in and then suddenly she said, you know, 'It was six o'clock I went on and it was half nine before I came off'. You have to keep reminding, you know, 'You don't need to be on all the time. You know your time to be online is this time'.

Given that the data are from teachers' lived experience, the following idea emerging from the data intrigued us. Teachers who were parents reported that home-schooling their own children was very challenging. They seemed to differentiate their teacher role from their parental role, thus separating the home-space strictly from the school-space, another binary with strict boundaries. However, the ease of access brought about by technology during the lockdown tested and blurred the divisions that both teachers/parents and children were accustomed to. Some teachers reported they had never acted as teachers to their own children:

as a parent myself, I never forced my children to do homework because I thought that they did enough at school, at home they were learning life skills... they were learning other things. And if they wanted to do it then I would support them, but I would never pressure them. But now. That's come back to bite me right in the behind. Because my kids are like... no, I'm not doing it... I'm not at school ... The worst part is trying to get them to do work, especially the older ones because they don't understand the gravity of what's going on.

In most of the interviews, teachers and Head Teachers were very quick to empathise with parents of the students they teach. "You can't force parents to do that. I know myself being a parent that it's really tricky. Trying to manage four kids! It would be tricky trying to manage even one kid especially if you're not au fait with technology and using these types of things. It's really, really hard".

Very often we speak of teachers and parents as opposing binaries. Yet from the data, we could see an in-between emerging: teachers as parents and parents as teachers. The 
very distinct identities were blurred through online engagement. Many teachers who were also parents reported being exasperated with some interactions between their own children and their children's teachers. Some also reported learning from these parental frustrations and trying to modify their own teaching practices accordingly: "I think because I've got my own children at home as well, some things that their teachers are doing are really annoying me. For example, I'm trying really hard to answer emails quickly- my daughter wrote an email to her teacher eleven days ago and didn't get an answer until today that was annoying. So, I'm trying to not do the things which are annoying me as a parent".

Some of the teachers were aware that particular teaching materials uploaded online created complex situations for parents as they had to mediate learning. One teacher called parents "surrogate teachers" saying that "what's harder has definitely for been parents ... They're quite clearly struggling". On the one hand teachers were aware that parents were needed to mediate teaching and learning, but on the other hand they were reluctant to put pressure on parents and impact on their parental relationship with the children: "Honestly, they need to be parents, that's all. We are not expecting them to be teachers. We're not. We don't want to. I don't want to. I don't want parents feeling pressure or stressed or getting upset ... they've got enough to contend with". Some teachers were actually asking: "As a school, what's our role as a school? To prepare children for life and work and learning' but you know, do we really prepare, prepare them for life?" Some teachers were arguing that maybe during the lockdown children should be learning basic skills, "taking this time to learn to cook and learn to budget and you know, so, you are actually looking at literacy and numeracy which of course will always be important, but suddenly the other subjects that are maybe, you don't have time for in the curriculum are coming to the forefront and you are actually seeing a greater value in them". Many teachers offered support to parents. Some teachers decided to do family learning tasks, where all the family were involved on a learning project, for example exploring animal habitats. Other developed online materials specifically for parents:

I've got a channel just for parents, which is just all about inspiration and hopefully I am answering questions about teaching and how I do things in the class, but well. In the hope that parents will absorb that and copy you, yeah? I've recorded myself, you know, even just reading stories, even recorded reading stories and. And hopefully you know that is helping parents to teach their children about reading and books...

\subsection{Theme Three: Learning New Concepts-Consolidating Concepts}

One of the tensions emerging from the data centres on teachers' understanding of teaching and learning during lockdown, what they perceive to be achievable using digital tools, and what is achievable within the restrictions imposed on use of digital tools by the educational hierarchy. This manifests as a tension between introducing new learning concepts or consolidating concepts that children had learnt prior to COVID-19, with one teacher reporting "we've been told to just be going over learning that they've already done this year rather than learning new concepts because they are not really able to do that on their own. So we've just kind of been doing learning that they've already done but trying to challenge them at the same time".

Some teachers were not certain that their use of technology could be conducive to new learning:

It's a mix, really. I think we haven't quite got the pedagogy right at all, and I don't even think that I do, so I would say right now that is definitely more challenging, how to do this in Technology. But I think everybody still trying to get their heads around how to teach this remotely. Because you can't really... we can't record a lesson and then send out to the pupils. You can do a video and then post it, but then it's not interactive for the kids. They can't really ask questions. so I don't think we've got the pedagogy right for remote teaching. In my assignments, I'm trying to make it very simple. Pointing them in directions of an online game, or, 
you know, unplug and go and play. But when you are depending on the parent in order to interpret what you've written it's difficult.

This previous comment alludes to the issue of learning new concepts being exacerbated in the first lockdown due to restrictions imposed by the educational hierarchy. Due to General Data Protection Restrictions (GDPR), to concerns about teacher workload, and about what was achievable beyond the physical school space, constraints were imposed; synchronous online sessions were not widely permitted and, where they were allowed, children's cameras were to be switched off. This meant that teachers were limited in their use of digital tools:

When we first got set up, I had assumed, 'Great, I can start doing group work and maybe have $4 . . .6$ kids at a time and do a discussion... have a proper lesson because they need that collaborative learning—oh it's such a loss. But Council rules are that there's absolutely completely no way, we are not allowed to video contact children, and presumably it's from a child protection point.

Other teachers reported being concerned about the loss of immediacy and connection because of these restrictions. The importance of responsive feedback and mediation were highlighted, and fear expressed about the impact of their lack on children's motivation and mastery of learning. The following comment reflects these concerns in a teacher who tried to mitigate them by tracking pupil's engagement:

You think of all the all the assistance we provide for them in school. It's all gone. They don't have an adult near them. They don't have a wee friend to ask. They don't have any collaborative learning, which is just the pits, and they're just.... the [attainment] gap is just going to become a chasm... I don't think I've really changed much in terms of the learning and teaching aspect, only because I'm just going to do the same lesson, but we will record it. And then, you know, pretend there's chat even though there's not chat, kind of thing. But then maybe don't know which of these children are actually tuning in. Yes, I do know my views are high because on YouTube it does tell you the numbers, but I don't know... it could be one kid watching the film 65 times.

Given the restrictions placed upon the application of the digital tools, some respondents felt it was particularly restrictive for teachers who felt they needed to engage more directly with their children due to the skill/knowledge being developed or the age of the children. This comment applies to the youngest school-aged children (age 5):

The most challenging thing is writing. There's always this kind of... I don't know whether it's perceived pressure or stress to get children writing, and that's a really, really hard thing to kind of balance with play-based learning in the class anyway, because traditionally we would be setting the kids down to write every day, or at least every week, or would be practising handwriting. And I can't see children's pencil grips. I can't see them, you know, to encourage them to start at the edge of the paper, or if their letter formation is the correct way. Those are things I kind of worry about at the back of my head because they're so difficult to unlearn ... And you know, I'm trying to kind of calm myself down about that whole writing. And can they, can they hold a pencil properly, can they form the letters properly? Can they spell properly? Can they write a sentence? Can they write on the line? Don't know.

Some teachers attempted to carve out spaces for new learning as a response to calls for differentiated teaching. They reported trying to find ways of working round restrictions and indeed sometimes paid lip service to these guidelines. The following comment reflects a teacher's thinking about how she could respond to children's saturation with learning consolidation. She thinks it possible to work around restrictions and use what she can within the digital space to teach new concepts, almost Foucauldian in her transgression: 
I am getting to the stage with some of my maths groups where they need to learn new stuff, and the unions have been really quite adamant that we shouldn't be teaching new ideas and that this time should be for consolidation. But I mean I've got a group who are sick to death of consolidation and word problems and problem solving and they just need to learn how to do taking away with crossing out. I've got a MS Teams chat with them tomorrow, just that maths group ... and I'm going to try and teach them it over video with no video - like audio chat.

Attention to the emotional and psychological demands of entering a national lockdown was a common theme within the interviews and it is possible that the choice to consolidate prior learning rather than deliver new learning was an expression of pastoral care rather than assumptions as to the utility of technologies. Indeed, comparing perceptions and practices relating to the acquisition of new learning between the first and second lockdown would provide valuable information as to developing attitudes and assumptions about learning in this new digital Thirdspace.

\section{Discussion}

This section addresses the results section and takes the data further into analysis. We have decided to address the themes as a whole which is based on the foundation of Soja's Thirdspace. We believe this is in line with our ontological and epistemological stance as outlined in the methodology section, as we agree with Hollway and Jefferson [9] that were we to address each theme in isolation such fragmentation of thought would diminish the argument we make. In fact, we start this discussion by referring to the impact of the school building and also the impact of its loss during lockdown on the binaries mentioned above. Elsewhere we have highlighted an increased awareness of the importance of the school building [14] as a site which allows for structures and processes to bring about equity and social justice [26]. The closure of the school building caused the necessity for innovative ways of ensuring the continued enactment of these two values, so that teachers and Head Teachers reported numerous creative initiatives in their attempts to reach out to all children, particularly those who were deemed vulnerable [26]. The three themes above similarly emerge due to the loss of the physical school building and the prominence of digital technology to connect people in its absence and are thus intertwined.

Prior to the lockdown, teachers were positioned in different places along the binary representing their views on technology: do they value technology in their teaching, and how comfortable are they using it. Our analysis pushed the school building to the forefront of this debate, as we realised that the binary effectively vanished once the schools closed. Whether teachers valued or were familiar with technology became a thing of the past, as technology became the medium through which all mainstream processes took place. In this way, we acknowledge that technology provides an in-between space, a Thirdspace that gives us more possibilities than we are accustomed to. As a Thirdspace, technology can escape being pinned down to particular ways of doing even if there are always attempts to pin it down. It seems to be in the nature of technology to constantly challenge teachers and students, as it eludes capture-hence guaranteeing a constant place in Thirdspace. It has an impact on the teachers who try to reach it, as it challenges their identities and their engagement with teaching and learning, as seen in the above themes. In Theme Three, the restrictions and constraints accompanying online teaching which were issued by governing bodies and unions effectively limited attempts of teachers to engage with it, to discover new ways of being with children. Thus, it is not only the technology itself, but also the politics that come with it, that have an impact.

We agree that technology is not neutral; it changes people and spaces (schools and homes) in their attempts to engage with it. Jones and Kessler [27] argue that teachers' agency and consequently their realisation of their identities were severely impacted by COVID-19 and our data suggests that engagement with technology contributed significantly to this impact. They quote a teacher describing "the need to separate her work from her personal life, something that in the COVID-19 era teachers have been increasingly un- 
able to do" (p. 3). One of the teachers in our study, in fact, remarked "that's tricky-being at home with my family and working at the same time... It's hard to switch off", while others reported purposefully reaching out to children and families by showing snippets of themselves in their personal lives. This ranged from one teacher who developed her numeracy lessons on her croft with her two-year old being very much present in her videos, to teachers attempting hand stands as part of a school challenge to encourage pupils' well-being.

... teachers are ... reacting according to their narrative understandings of selves, schools, and students ... teachers are now dealing with a complete disruption of their storied professional landscape and, therefore, their sense of how they know themselves and their students. Formerly, "changes ripple[d] through the school and influence the whole web of stories" (Clandinin and Connelly, 1996, p. 160), now the changes have come as something akin to a forest fire, requiring a full remaking of the landscape and teachers' stories of self [27].

Many teachers in the above themes mentioned the wide range of digital tools and spaces that work on different digital platforms. This choice may place teachers under some pressure as they need to keep up with this ever-changing digital scenario, where no sooner are teachers familiar with digital platforms than they are presented with new ones to use as media for their teaching, risking appearing dated if they do not keep up. This pressure is felt by technology users and sits alongside Camilleri's [28] argument that the perceived utility of a technology is related to an individual user's familiarity with that technology within the context it is to be employed within. Castells [29] describes users as the 'key producers' of technology, moulding the technology to reflect their values and meet current needs. In this regard the technology itself is transformed by the user's beliefs, values and assumptions. Orlikowski [30] captures this dynamic by describing technologies as embodied structures, built to be appropriated by users. Locating these ideas within the context of education, Mays [31] suggests that, for technologies to be used for purposes beyond replicating and scaling traditional learning and teaching approaches, teachers must approach technologies open to new possibilities. Indeed, Mays [31] argues that assumptions about pedagogy, engagement and what is 'possible' are nested within the very design of the digital learning pathways and opportunities created by educators. Yet, although our research did yield data which showed technology as malleable and flexible for those who claimed familiarity with it, other accounts reflected a view of technology as a stronger force, indeed one which pulled them out of their comfort zone. In fact, this may also be the case once teachers are familiar with a digital platform, as they may unexpectedly be asked to engage with an upgrade or even a completely different platform. Baumans' [32] theory of liquid modernity argues that, as society moves forward, the pace of change also quickens in many aspects of that society. As this pace of change quickens, what was previously seen as new now has an increasingly reduced lifespan to be replaced by the new. The recently new is now seen to be old-fashioned. If we apply this theory to education and digital technologies, how does this impact on the teacher? Is there still the space and time for that shared grammar of developing practice to take seed, to grow and to flourish?

This liquidity of change is one that is very much linked to the promise of transformation of teaching and learning made to schools by the major educational technology companies. This promise is one that can be seen in the literature and at events such as educational trade shows [33,34]. Indeed, Buckingham [33] (p. 26) in his critique of how digital technology is sold to education argues that, "technology seems to move beyond being a mere consumer product and to assume an almost metaphysical dimension; and in the process, it is endowed with a magical ability to stimulate and transform learning and teaching". We feel this is suggestive of Soja's ephemeral and elusive nature of what inhabits Thirdspace as it "introduces a critical 'other-than' choice that speaks and critiques through its otherness... It does not derive simply from an additive combination of its binary antecedents but rather from a disordering, deconstruction, and tentative reconstitution of their presumed totalization producing an open alternative that is both similar and strik- 
ingly different" [8] (p. 61). In this Thirdspace, "contradictory and seemingly incompatible ideas [are allowed] to coexist and be creatively restructured in new ways to produce new meaning" [35] (p. 57).

Despite some reticence about technology use in schools [36,37] and the nature of engagement with it as dictated by the educational hierarchy, many teachers in Scotland had little option but to try to engage with it at various levels. It was evident from our data that there are different attitudes among teachers' use of technology in their practice, and this is supported by international literature [38-42]. The promise of transformation is a seductive one for education and one that could be argued, from a Scottish perspective, is still a promise that many see as unfulfilled. Indeed, commentators such as Selwyn [43] (p. 9) argue that much of the rhetoric of transformation is very difficult to substantiate. Mays' [31] analysis points out that new media and technology can easily be used simply to replicate the traditional teaching and learning approaches rather than offering new approaches. Selwyn [43] further argues that we should treat descriptions of digital revolution, transformation and improvement as evocative and aspirational stories, rather than sober, objective and accurate descriptions of actual ongoing changes in education. As Higgins et al. [44] (p. 16) argue, "overall the key implication is that the technology is solely a catalyst for change. What is it that teachers or learners actually do which brings about any improvement in learning? Focusing on the change (and the process of change) in terms of learning is essential in supporting effective use." The lockdown has highlighted that, when it comes to effective teaching and learning with digital tools and spaces, we still "don't have a shared picture of what effective practice with digital technologies look like" [45] (p. 3). As Mays [31] argues, new tools should not replicate what has always been done but are ideally used to rethink what is both desirable and possible in an online environment.

It was against this backdrop of an apparent deficit understanding of digital pedagogy in the traditional school-based space of teaching and learning that teachers found themselves wrestling with online teaching. Ewing and Cooper used the term 'instructional MacGyvers' to describe how teachers were feeling during the pandemic, having to improvise solutions in less than ideal circumstances [3]. Arguably, it is the case that what has become the default discourse around digital technologies is the need first and foremost to develop confidence and competence in tools against the already discussed backdrop of rapid change. This rapid change brings into question whether there was the time, and even an appreciation of the importance of going beyond a functional competence and to explore the underlying pedagogies of digital teaching and learning irrespective of the tool, space or device used. Lockdown presented the teaching profession with a new challenge and a new space in which it had to make sense of what it means to be an educator in the challenging context of a lockdown caused by a pandemic.

\section{Conclusions}

This paper looked at the impact of digital technology on teaching and learning in primary schools in Scotland during the first COVID-19 lockdown, based on a study on the lived experiences of primary teachers working in Scotland during this time. As Jones and Kessler [27] remarked, "during the pandemic, the entire landscape of teachers' realities has shifted. Initially, this took place overnight, while public discourse continued to demand their accountability. While attempting to adapt her practices and materials for virtual teaching in March of 2020, a teacher's identity may have undergone one round of renegotiation, reconceptualizing her teaching values or commitments for a new modality" (p. 6). This was also reflected in Kim and Asbury's [46] research.

This paper discusses that Scotland was similar to many other countries internationally in that lockdown revealed a lack of preparedness to switch to online learning and understanding of how to engage with digital technologies and pedagogies. Against this backdrop, Soja's concept of Thirdspace helped us read the data through several binaries, where technology was viewed as providing a space, and itself also being an in-between space, a Thirdspace that gives us more possibilities than we are accustomed to. These pos- 
sibilities, in the data analysed from the Scottish digital context, reveal that the teachers in this study were able to realise more meaningful engagement in the digital Thirdspace than had been possible, or perceived as desirable, prior to lockdown. However, the different levels of engagement and consequent competence of teachers with digital technology mean that some teachers, who had previously been very successful in their class teaching, were perceived differently and those with digital expertise were finally able to demonstrate the value of their prior engagement with digital technology. The introduction of the virtual arena of teaching and learning meant that previously well-defined binaries of teachers in school and parents at home meant that roles became blurred; teachers who were also parents found it challenging to manage both roles and had to find an-other way of being in their home while students' parents became intermediaries for their children and teachers to support the digital channel of communication. The Scottish Government guidance for parents not to act formally as teachers was challenging to enact in their lived reality.

A final tension concerned what was possible in terms of introducing new learning versus consolidation of learning. This was due to teachers' own uncertainty about what was achievable using digital tools exacerbated by well-meaning restrictions imposed upon how they and their students were permitted to engage with the technology. Technology, as a Thirdspace, can support teaching and learning to escape being pinned down to particular ways of doing and contradictory ideas can co-exist. It is this light that technology is seen as hopeful for teachers and students, yet as well always being a receding horizon that always needs to be aimed at. The COVID-19 lockdown brought this complexity into sharp focus. Moving forward, it is fundamental that educational policies reconceptualise how digital technology can support learning. This would enable teachers and learners to build on what lockdown has shown us to be possible and may support educational structures that transcend our embedded understanding of teaching and learning being always centred around and restricted to the local, physical environs of the school. It is hoped that, as COVID-19 becomes managed, we retain the value of what we have learned as we return to schools and the physical locus of learning and with the reinstating of previous binaries.

Author Contributions: All authors listed have made a substantial, direct, and intellectual contribution to the work and approved it for publication. All authors have read and agreed to the published version of the manuscript.

Funding: This research received no external funding.

Institutional Review Board Statement: The study was conducted according to the guidelines of the Declaration of Helsinki, and approved by the Institutional Review Board (or Ethics Committee) of University of Dundee (protocol code E2019-83 and date of approval 3 April 2020).

Informed Consent Statement: Informed consent was obtained from all subjects involved in the study.

Data Availability Statement: The datasets presented in this article are not readily available because the dataset is only available to the research team. Requests to access the datasets should be directed to corresponding author.

Conflicts of Interest: The authors declare no conflict of interest.

\section{References}

1. The World Bank Education Global Practice Guidance Note: Remote Learning \& COVID-19. Available online: https:// openknowledge.worldbank.org/handle/10986/33585 (accessed on 15 January 2021).

2. König, J.; Jäger-Biela, D.J.; Glutsch, N. Adapting to online teaching during COVID-19 school closure: Teacher education and teacher competence effects among early career teachers in Germany. Eur. J. Teach. Educ. 2020, 43, 608-622. [CrossRef]

3. Ewing, L.; Cooper, H. Technology-enabled remote learning during COVID-19: Perspectives of Australian teachers, students and parents. Technol. Pedagog. Educ. 2021. [CrossRef]

4. Darling-Hammond, L.; Burns, D.; Campbell, C.; Goodwin, A.L.; Hammerness, K.; Low, E.L.; Sat, M.; Zeichner, K. Empowered Educators: How High-Performing Systems Shape Teaching Quality around the World; Jossey-Bass: San Francisco, CA, USA, 2017.

5. Humes, W.; Bryce, T. The Distinctiveness of Scottish Education; Bryce, T.K.G., Humes, W., Gillies, D., Kennedy, A., Eds.; Edinburgh University Press: Edinburgh, UK, 2018; pp. 118-128. 
6. United Nations Policy Brief. Policy Brief: The Impact of COVID-19 on Children. 2020. Available online: https://unsdg.un.org/ sites/default/files/2020-04/160420_Covid_Children_Policy_Brief.pdf (accessed on 3 February 2021).

7. Darling-Hammond, L. Powerful Teacher Education: Lessons from Exemplary Programs; Wiley and Sons: San Francisco, CA, USA, 2006.

8. Soja, E.W. Thirdspace: Journeys to Los Angeles and Other Real-and-Imagined Places; Blackwell: Cambridge, UK, 1996.

9. Hollway, W.; Jefferson, T. Doing Qualitative Research Differently; Sage Publications: London, UK, 2000.

10. Hollway, W. Subjectivity and Method in Psychology: Gender, Meaning and Science; Sage Publications: London, UK, 1989.

11. Hayes, N. (Ed.) Theory-led thematic analysis: Social identification in small companies. In Doing Qualitative Analysis in Psychology; Psychology Press/Erlbaum Taylor \& Francis: London, UK, 1997; pp. 93-114.

12. Rogers, C. A Therapist's View of Psychotherapy_On Becoming a Person; Constable: London, UK, 2001.

13. Scottish Education Research Association. Teaching and Learning in lockdown in Scotland. November 2020. Available online: https:/ / sites.dundee.ac.uk/teachers-covid-19-lockdown/ (accessed on 18 March 2021).

14. McLennan, C.; Mercieca, D.; Mercieca, D.P. What can I do? Caring relationships among teachers, students and families during COVID-19 lockdown in Scotland. Malta Rev. Educ. Res. 2020, 14, 163-181.

15. Bhabha, H.K. The Location of Culture; Routledge: New York, NY, USA; London, UK, 1994.

16. Beech, N. Liminality and practices of identity construction. Hum. Relat. 2011, 64, 285-302.

17. Potter, J.; McDougall, J. Digital Media, Culture and Education Theorising Third Space Literacies; Palgrave Macmillan: London, UK, 2017.

18. Moje, E.B.; Ciechanowski, K.M.; Kramer, K.; Ellis, L.; Carrillo, R.; Collazo, T. Working toward third space in content area literacy: An examination of everyday funds of knowledge and Discourse. Read. Res. Q. 2004, 39, 38-70. [CrossRef]

19. Shulman, L.S. Signature pedagogies in the professions. Daedalus 2005, 134, 52-59. [CrossRef]

20. Scottish Government. Enhancing Learning and Teaching through the Use of Digital Technology: A Digital Learning and Teaching Strategy for Scotland. 2016. Available online: http:/ / www.gov.scot/Publications/2016/09/9494/0 (accessed on 5 December 2020).

21. The Scotsman. The Force Is with Glow as Virtual Help Links up Schools. 2008. Available online: https://www.scotsman.com/ news / force-glow-virtual-help-links-schools-2463328 (accessed on 5 December 2020).

22. Scottish Government. International Council of Education Advisers Report 2018-2020. 2020. Available online: https:/ /www.gov. scot/publications/international-council-education-advisers-report-2018-2020/ (accessed on 5 December 2020).

23. Scottish Government. Coronavirus (COVID 19)_Impact on Education: Deputy First Minster Speech. 2020. Available online: https://www.gov.scot/publications/statement-covid19-managing-impacts-scottish-education/ (accessed on 19 March 2020).

24. Scottish Government. Coronavirus (COVID 19)—Supporting Pupils, Parents and Teachers—Learning during Term 4. 2020. Available online: https:/ / www.gov.scot/publications/supporting-pupils-parents-teachers-learning-during-term-4/ (accessed on 20 March 2020).

25. Stiegler, B. Taking Care of Youth and the Generations; Stephen Barker (tr.); Stanford University Press: Stanford, CA, USA, 2010.

26. Ferguson, P.; McKenzie, M.; Mercieca, D.; Mercieca, D.P.; Sutherland, L. Primary Head Teachers' Construction and Re-negotiation of Care in COVID-19 Lockdown in Scotland. Front. Educ. 2021, 6, 617869. [CrossRef]

27. Jones, A.L.; Kessler, M.A. Teachers' Emotion and Identity Work During a Pandemic. Front. Educ. 2020, 5, 583775. [CrossRef]

28. Camilleri, P. The Ghost in the Machine. A Structurational Interpretation of Maltese Policies on ICT and Education. Malt. Rev. Educ. Res. 2017, 11, 127-147.

29. Castells, M. The Internet Galaxy. Reflections on the Internet, Business, and Society; Oxford University Press: Oxford, UK, 2002.

30. Orlikowski, W.J. Using Technology and Constituting Structures: A Practice Lens for Studying Technology in Organizations. Organ. Sci. 2000, 11, 404-428. [CrossRef]

31. Burgos, D.; Tlil, A.; Tabacco, A. Radical Solutions for Education in a Crisis Context-COVID-19 as an Opportunity for Global Learning; Springer: London, UK, 2021.

32. Bauman, Z. Liquid Modernity; Blackwell: Oxford, UK, 2000.

33. Buckingham, D. Beyond Technology: Children's Learning in the Age of Digital Culture, (Illustrated ed.); Polity Press: Cambridge, UK, 2007.

34. Player-Koro, C.; Rensfeldt, A.B.; Selwyn, N. Selling tech to teachers: Education trade shows as policy events. J. Educ. Policy 2018, 33, 682-703. [CrossRef]

35. Lauer, C. Constructing the Self in/as Thirdspace: New Potentials for Identity Exploration in the Composition Classroom. Compos. Stud. 2009, 37, 53-74.

36. Kist, W.; Pytash, K.E. "I love to flip the pages": Preservice teachers and new literacies within a field experience. Engl. J. 2015, 104, 131-167.

37. Laughter, J. ELA teacher preparation 2.0: Critical media literacy, action research, and mashups. Contemp. Issues Technol. Teach. Educ. 2015, 15, 265-282.

38. Kim, C.; Keller, J. Towards technology integration: The impact of motivational and volitional email messages. Educ. Technol. Res. Dev. 2011, 59, 91-111. [CrossRef]

39. Lemon, N.; Garvis, S. Pre-service teacher self-efficacy in digital technology. Teach. Teach. 2016, 22, 387-408. [CrossRef] 
40. Wake, D.; Whittingham, J. Teacher candidates' perceptions of technology supported literacy practices. Contemp. Issues Technol. Teach. Educ. 2013, 13, 175-206.

41. Wastiau, P.; Blamire, R.; Kearney, C.; Quittre, V.; Van de Gaer, E.; Monseur, C. The use of ICT in education: A survey of schools in Europe. Eur. J. Educ. 2013, 48, 11-27. [CrossRef]

42. Spiteri, M.; Chang Rundgren, S. Literature Review on the Factors Affecting Primary Teachers' Use of Digital Technology. Technol. Knowl. Learn. 2020, 25, 115-128. [CrossRef]

43. Selwyn, N. Is Technology Good for Education? Polity Press: Cambridge, UK, 2016.

44. Higgins, S.; Xiao, Z.; Katispataki, M. The Impact of Digital Technology on Learning. 2012. Available online: https:// educationendowmentfoundation.org.uk/evidence-summaries/evidence-reviews/digital-technology/\# (accessed on 3 November 2020).

45. McFarlane, A. Growing up Digital: What Do We Really Need to Know about Educating Her Digital Generation? 2019. Available online: https: / www.nuffieldfoundation.org/sites/default/files/files/Growing\%20Up\%20Digital\%20-\%20final.pdf (accessed on 5 November 2019).

46. Kim, L.E.; Asbury, A. 'Like a rug had been pulled from under you': The impact of COVID-19 on teachers in England during the first six weeks of the UK lockdown. Br. J. Educ. Psychol. 2020, 90, 1062-1083. [CrossRef] [PubMed] 